\title{
Development of Models to Estimate Solar Radiation for Chinese Locations
}

\author{
Qingyuan Zhang*1, Joe Huang ${ }^{2}$, Yang Hongxing ${ }^{3}$ and Lou Chengzhi ${ }^{4}$ \\ ${ }^{1}$ Professor, Tsukuba College of Technology, Japan \\ ${ }^{2}$ Staff Scientist, Lawrence Berkeley National Laboratory, USA \\ ${ }^{3}$ Associate Professor, The Hong Kong Polytechnic University, China \\ ${ }^{4}$ Associate Professor, Tianjin University, China
}

\begin{abstract}
In this paper, using two databases of observed weather data for the major cities in China, we developed models with three variables to estimate hourly solar radiation on the horizontal surfaces for these cities. The errors in estimating solar radiation in different locations were discussed. Two methods to estimate monthly solar radiation were developed and compared. Models to estimate yearly solar radiation were also developed using latitude, elevation and average cloud cover.
\end{abstract}

Keywords: China, solar radiation, observation, models, estimation

\section{Introduction}

Weather is one of the primary determinants of indoor thermal conditions and space conditioning energy use. In building simulations, solar radiation is one of the most important meteorological elements, because solar radiation influences both heating and cooling loads significantly.

There are two major barriers in finding observed solar data in China: (1) although the Chinese weather service has recorded weather data for all major cities for several decades, most of the data are not in a digital format, making their transcription and purchase prohibitively expensive, (2) solar data, when available, usually consist of daily total horizontal and diffuse solar radiation, which is especially true before 1992. Therefore it is necessary to develop some models to estimate solar radiation in the major cities in China in order to produce solar data and add them to the observation databases. Cui et al. ${ }^{1)}$ tried to estimate solar data for Beijing and Shanghai using measured dry-bulb temperature, humidity, cloud cover and wind speed, but encountered problems in interpolating between the six-hour intervals. The authors developed models to estimate solar radiation using measured dry-bulb temperature etc. at three-hour intervals ${ }^{2}$. The estimated values of solar radiation agree with measured values in Beijing and Guangzhou in 1993, but the accuracy of estimation could not be verified for other cities due to insufficient observed data.

In this paper, using two databases of observed weather

*Contact Author: Qingyuan Zhang, Professor,

Tsukuba College of Technology

4-3-15 Amakubo, Tsukuba, 305-0005 Japan

Tel\&Fax: +81(0)29-858-9376

e-mail: zhang@a.tsukuba-tech.ac.jp

(Received May 8, 2003; accepted September 1, 2003) data for the major cities in China, we developed models with three variables to estimate hourly solar radiation on the horizontal surfaces for these cities. The errors in estimating solar radiation in different locations were discussed. Two methods to estimate monthly solar radiation were developed and compared. Models to estimate yearly solar radiation were also developed using latitude, elevation and average cover cloud.

\section{Source Data for Solar Models}

Two databases of weather data were used in establishing the solar models: one is the database of International Surface Weather Observations ${ }^{3)}$ which is called the ISWO database; another one is the observed solar data in 1993 for 24 major cities of China ${ }^{4}$, which is called OSR database in this study. The ISWO database consists of dry-bulb temperature, dew point temperature, the amounts of cloud cover, wind speed etc. from observation in the period of 1982-1998 at three-hour intervals, but there are not any solar radiation data included in the database. The ISWO database covers more than 70 major cities in China. On the other hand, only data of observed solar radiation in 1993 are included in the OSW database with one-hour intervals. Therefore, it is necessary to combine these two databases to develop models to estimate solar radiation for the ISWO database in order to develop the Typical Meteorological Years and other uses.

\section{Models to Estimate Hourly Solar Radiation}

In order to estimate the hourly solar radiation for the cities included in the ISWO database, it is necessary to find relations between solar radiation and other variables. Cui et al. ${ }^{1)}$ showed the correlation between solar radiation and temperature change from previous hours, the amount of cloud cover, relative humidity and wind speed at sixhour intervals, but the accuracy was not sufficient due 
to the large time intervals. It is possible to improve the accuracy using the data from ISWO database because the observation intervals are smaller (three hours) than that of Cui's. Also it is possible for us to develop models which are applicable to more locations because there are solar data included in the OSR database for 24 locations.

In order to select parameters in the models to estimate solar radiation, the relations between solar radiation and other variables like the amount of cloud cover, temperature changes, relative humidity are examined.

It is obvious that increase in ambient temperature is mainly the results of solar radiation. Therefore there should be some relations between solar radiation and temperature changes. Figure 1 shows the relations between hourly global radiation on the horizontal surface and temperature change from previous three hours in Beijing. It is clear that a strong correlation exists between them.

The amount of cloud cover can be another parameter to estimate solar radiation because solar radiation reaching the ground surface is filtered by cloud all the time. It is reported that the percentage of sunshine has a strong correlation with the global solar radiation on the horizontal surface ${ }^{5)}$, but it is difficult to estimate solar radiation with the percentage of sunshine due to lack of observed data of this percentage in the ISWO and OSW databases.

Figure 2 shows the relationship between the global solar radiation on the horizontal surface and the total cloud cover. The relationship between the two variables is approximated by a quadratic equation instead of a linear equation. The maximum value of solar radiation does not appear at the point when the cloud cover is zero but at the amount of three to four. This is because that the strongest solar radiation appears when the radiation comes from both the sun and cloud but not from the sun only.

The relationship between the global solar radiation on the horizontal surface and relative humidity is also examined. As shown in Fig.3, relative humidity has a negative correlation to solar radiation. Therefore relative humidity can also be considered as one of the variables to estimate solar radiation.

The relationship between solar radiation and wind speed is also examined, but little relation can be found between them, therefore wind speed is not included as a variable in estimating solar radiation.

Multiple regressions were carried out to establish models to estimate hourly solar radiation. Based on the discussion above, dry-bulb temperature changes, total amount of cloud cover and relative humidity were adopted as variables as shown in Equation 1.

$$
\begin{aligned}
I_{h} & =\left[I _ { 0 } \cdot \operatorname { s i n h } \cdot \left\{C_{0}+C_{1} \cdot \frac{C C}{10}+C_{2} \cdot\left(\frac{C C}{10}\right)^{2}\right.\right. \\
& \left.\left.+C_{3} \cdot\left(\theta_{n}-\theta_{n-3}\right)+C_{4} \phi\right\}-C_{5}\right] / k
\end{aligned}
$$

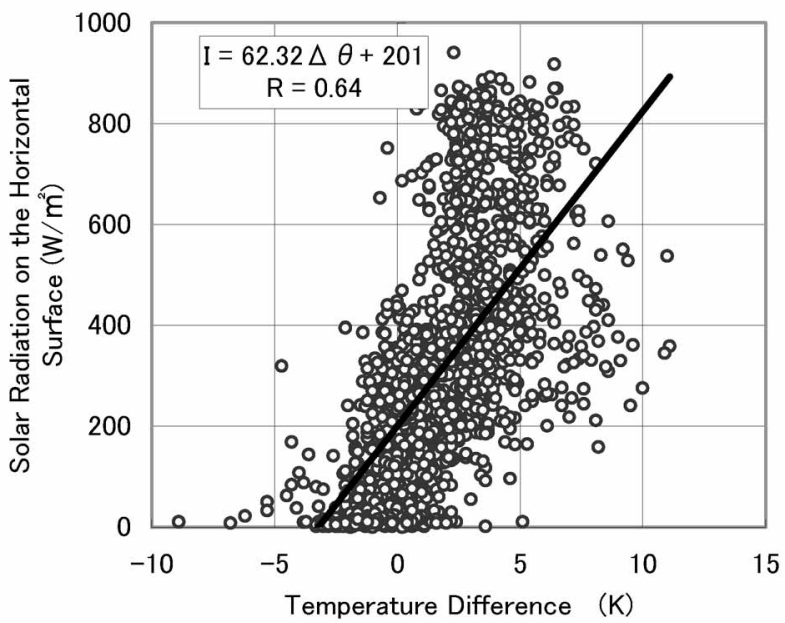

Fig.1. Correlation between Solar Radiation and Temperature Difference

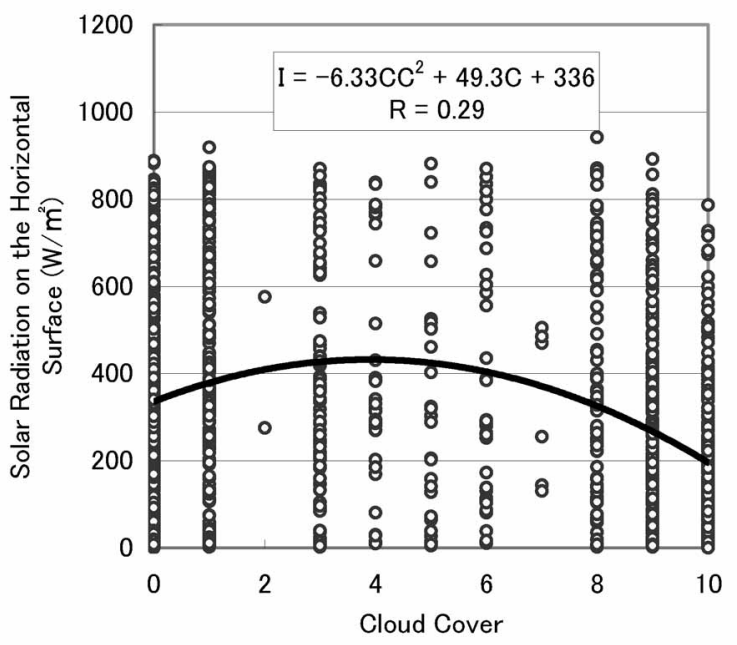

Fig.2. Correlation between Solar Radiation and Cloud Cover

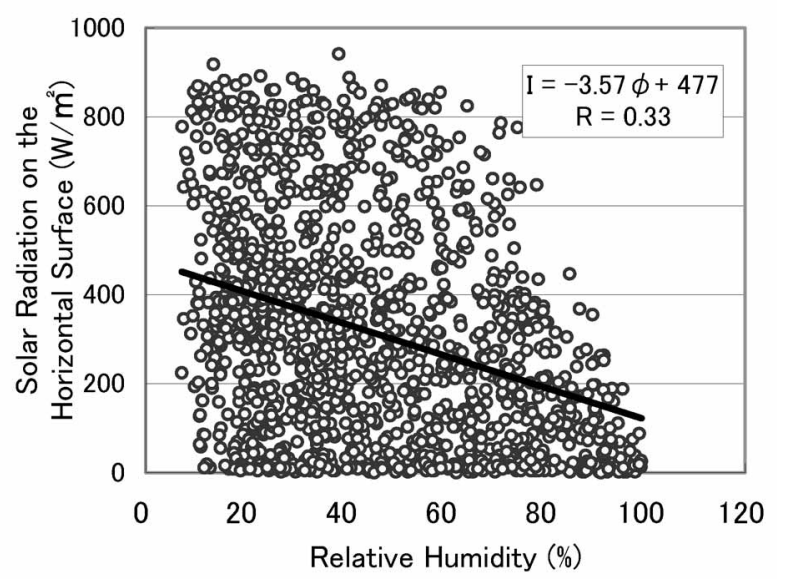

Fig.3. Correlation between Solar Radiation and Relative Humidity 
Table 1. Variables in Equation 1 for Different Cities

\begin{tabular}{|c|c|c|c|c|c|c|c|c|c|}
\hline Cities & $\mathrm{C}_{0}$ & $\mathrm{C}_{1}$ & $\mathrm{C} 2$ & $\mathrm{C} 3$ & $\mathrm{C} 4$ & $\mathrm{C} 5$ & $\mathrm{k}$ & $\mathrm{R}$ & $\mathrm{RMSE}$ \\
\hline \hline BEIJING & 0.6584 & 0.4864 & -0.6647 & 0.0203 & -0.0039 & 36.6114 & 0.9300 & 0.97 & 80 \\
\hline CHANGCHUN & 0.8412 & 0.4406 & -0.6853 & 0.0021 & -0.0047 & 40.2260 & 0.8868 & 0.94 & 116 \\
\hline CHANGSHA & 0.7085 & 0.7065 & -0.9413 & 0.0230 & -0.0038 & 42.2020 & 0.8747 & 0.94 & 84 \\
\hline CHENGDU & 0.3645 & 0.4800 & -0.6335 & 0.0495 & -0.0011 & 40.5660 & 0.8250 & 0.92 & 103 \\
\hline FUZHOU & 0.7960 & 0.7279 & -0.9365 & 0.0200 & -0.0052 & 35.7491 & 0.9112 & 0.94 & 96 \\
\hline GUANGZHOU & 0.6050 & 0.5755 & -0.7893 & 0.0278 & -0.0030 & 36.8362 & 0.8998 & 0.95 & 87 \\
\hline GUIYANG & 0.4688 & 0.4750 & -0.7223 & 0.0321 & -0.0008 & 38.3084 & 0.8743 & 0.93 & 96 \\
\hline HANGZHOU & 0.4378 & 0.8395 & -1.1174 & 0.0408 & -0.0001 & 41.3412 & 0.8702 & 0.91 & 115 \\
\hline HARBIN & 1.0235 & 0.5162 & -0.6877 & -0.0056 & -0.0063 & 35.0285 & 0.8924 & 0.93 & 136 \\
\hline HEFEI & 0.8084 & 0.6724 & -0.8846 & 0.0189 & -0.0051 & 35.6732 & 0.9197 & 0.96 & 88 \\
\hline JINAN & 0.6497 & 0.4679 & -0.6317 & 0.0242 & -0.0038 & 27.2746 & 0.9178 & 0.96 & 88 \\
\hline KUNMING & 0.4817 & 0.2936 & -0.5768 & 0.0403 & 0.0003 & 43.9962 & 0.8745 & 0.93 & 137 \\
\hline LHASA & 0.6996 & -0.0929 & -0.2399 & 0.0162 & 0.0026 & 56.6359 & 0.8811 & 0.94 & 165 \\
\hline LANZHOU & 0.3545 & 0.6723 & -0.8564 & 0.0430 & 0.0007 & 40.8254 & 0.8954 & 0.95 & 110 \\
\hline NANCHANG & 0.7638 & 0.8086 & -1.0198 & 0.0348 & -0.0048 & 35.5071 & 0.9192 & 0.96 & 90 \\
\hline NANNING & 0.4989 & 0.7322 & -0.9156 & 0.0402 & -0.0020 & 42.7619 & 0.8687 & 0.93 & 114 \\
\hline NANJING & 0.7586 & 0.5914 & -0.7919 & 0.0181 & -0.0050 & 31.8024 & 0.9350 & 0.97 & 76 \\
\hline SHENYANG & 0.8199 & 0.6304 & -0.8533 & 0.0035 & -0.0051 & 39.2128 & 0.9047 & 0.96 & 98 \\
\hline TIANJIN & 0.7297 & 0.5113 & -0.7432 & 0.0118 & -0.0036 & 38.6689 & 0.9110 & 0.97 & 106 \\
\hline WUHAN & 0.7395 & 0.7426 & -0.9817 & 0.0276 & -0.0043 & 37.0186 & 0.9123 & 0.96 & 90 \\
\hline XIAN & 0.5283 & 0.6062 & -0.7861 & 0.0353 & -0.0024 & 36.6207 & 0.9070 & 0.96 & 91 \\
\hline XINING & 0.3856 & 0.6237 & -0.8658 & 0.0376 & 0.0015 & 41.7887 & 0.8910 & 0.94 & 122 \\
\hline YINCHUAN & 0.5831 & 0.4261 & -0.7089 & 0.0282 & -0.0006 & 37.4911 & 0.9237 & 0.96 & 105 \\
\hline ZHENGZHOU & 0.7085 & 0.5092 & -0.7069 & 0.0165 & -0.0037 & 37.0826 & 0.9250 & 0.97 & 86 \\
\hline
\end{tabular}

where $I h$ is the estimated hourly global solar radiation on the horizontal surface in $\mathrm{W} / \mathrm{m}^{2} ; I_{0}$ is the solar constant, $1354 \mathrm{~W} / \mathrm{m}^{2} ; C C$ is the amount of cloud cover in tenths; $\theta_{\mathrm{n}}$ and $\theta_{\mathrm{n}-3}$ are dry-bulb temperature at hours $\mathrm{n}$ and $\mathrm{n}-3$, respectively; $h$ is the sun's altitude and the term $\left(I_{0} \sin h\right)$ means solar radiation on the horizontal surface in the outer space; $\phi$ is relative humidity in $\% ; C_{1} \ldots C_{5}$ and $k$ are regression coefficients, the values of which differ from place to place as shown in Table 1. The coefficients of correlation $R$ for all the 24 locations are between 0.91 and 0.97 with maximum error of $137 \mathrm{~W} / \mathrm{m}^{2}$ except for Lhasa. The error for Lhasa is larger than that for other locations because the total amount of solar radiation in Lhasa is also much stronger than other locations.

The relationship between the observed solar radiation and the values from Equation 1 for Beijing is shown in Figure 4 . The correlation coefficient $R$ is 0.97 , and the root mean square errors of the estimation is $80 \mathrm{~W} / \mathrm{m}^{2}$, which implies that Equation 1 can be used to estimate the hourly horizontal solar radiation with good accuracy in Beijing. Similarly, the relationship between the estimated and observed solar radiation in Guangzhou in the south and Harbin in the north are shown in Fig.5 and Fig.6. Based on these figures and Table 1, it is reasonable to conclude that Equation 1 can be used to estimate hourly global solar radiation on the horizontal surface for the 24 Chinese locations.

\section{Models to Estimate Monthly Solar Radiation}

Monthly solar radiation is required in some energy calculations of buildings. One of the methods to calculate monthly solar radiation is to sum up hourly solar radiation estimated with Equation 1 throughout the month. Figure 7 shows a comparison of monthly solar radiations from observation and estimation from Equation 1 for Beijing in 1993. The values from observation and estimation agree with each other well in most months throughout the year.

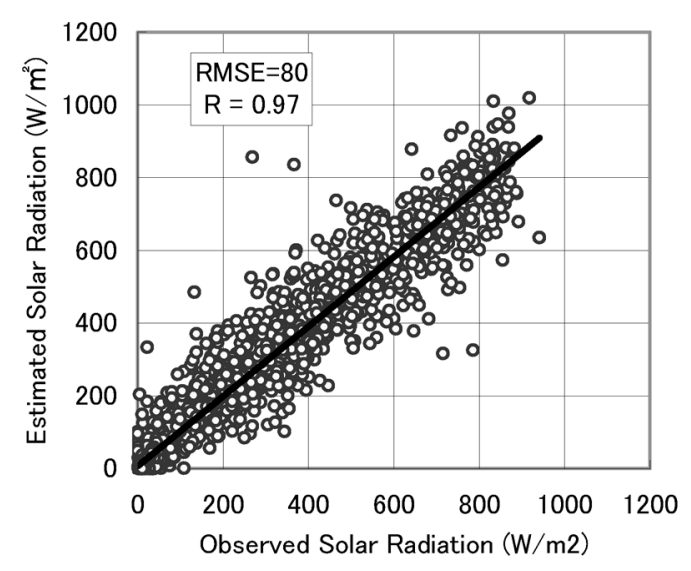

Fig.4. Correlation between Obseved and Estimated Solar Radiation by Equation1 (Bejing. 1993) 


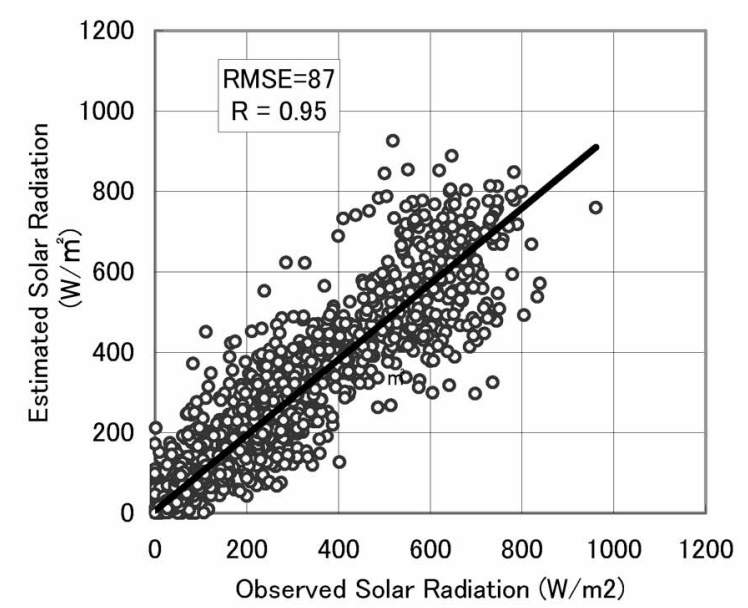

Fig.5. Correlation between Observed and Estimated Solar Radiation by Equation 1 (Guangzhou 1993)

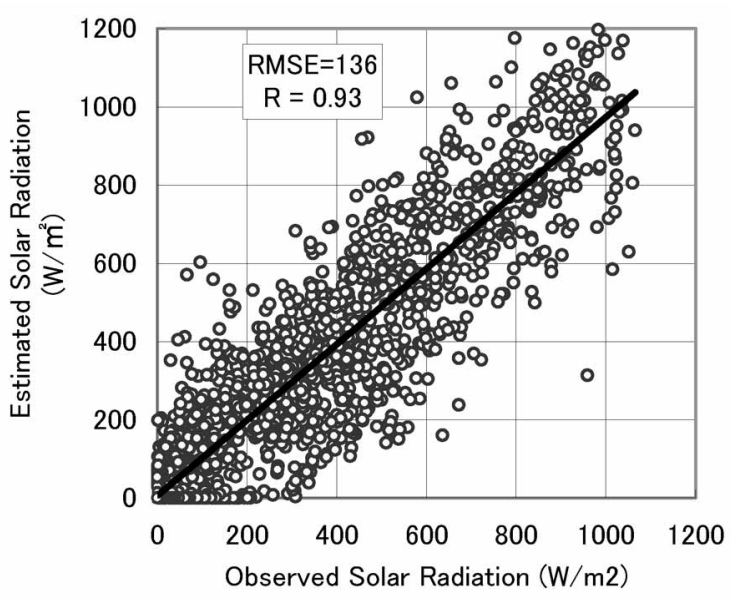

Fig.6. Correlation between Observed and Estimated Solar Rediation by Equation 1 (Harbin, 1993)

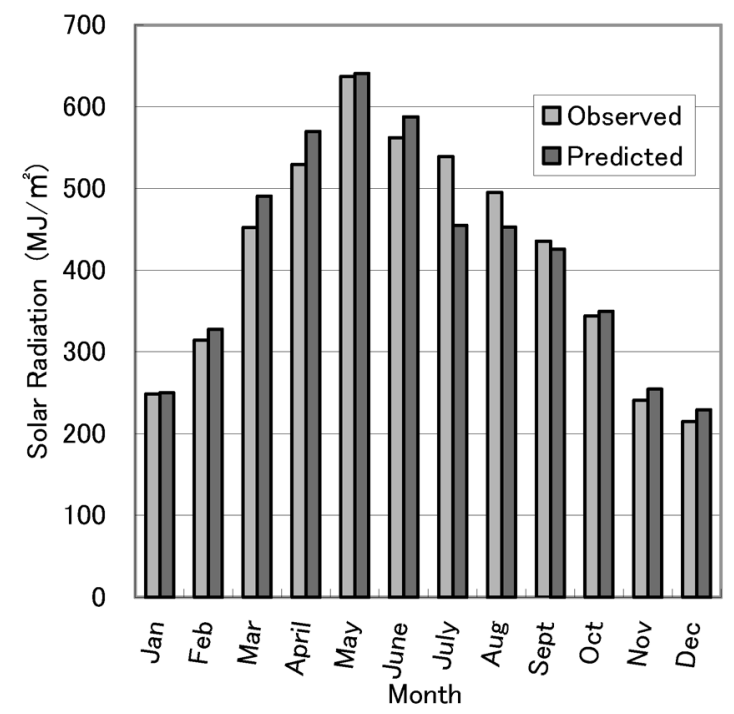

Fig.7. Comparison of Observed and Predicted Solar Radiation on the Horizontal Surface in Bejing
Table 2 shows the comparison of monthly solar radiation from observation and estimation with Equation 1 for the 24 Chinese cities in 1993. The data of monthly solar radiation listed here can also serve as the material of building energy calculations because very few data on solar radiation about Chinese locations have been published up to now. The monthly solar radiation estimated with Equation 1 and coefficients in Table 1 for each location agrees with observation with minor errors.

The main problem to estimate monthly solar radiation using Equation 1 is that one has to calculate solar radiation hourly, and sum them up throughout the month. Without hourly observed data of dry-bulb temperature, relative humidity and cloud cover, it is impossible to estimate monthly solar radiation with this method. To simplify the procedure of estimating the monthly solar radiation, a new equation is developed in the form of Equation 2, using elevation, latitude and monthly average cloud cover as variables by multivariate analysis.

$$
\mathrm{I}_{\mathrm{m}}=\mathrm{d}_{0}+\mathrm{d}_{1} \cdot \mathrm{H}+\mathrm{d}_{2} \cdot \psi+\mathrm{d}_{3} \cdot \overline{\mathrm{CC}}_{\mathrm{m}}
$$

where $\overline{\mathrm{CC}} \mathrm{m}$ is monthly average cloud cover; $d_{0} \ldots d_{3}$ are regression coefficients shown in Table $3 ; H$ is the elevation of a location in $\mathrm{m}$; $\Psi$ is the latitude; $I m$ is the monthly accumulated solar radiation on the horizontal surface in $\mathrm{MJ} / \mathrm{m}^{2}$. As shown in Table 3, the values of $d_{0} \cdots d_{3}$ are different for different months. Coefficients of correlation R and errors of estimation (RMSE) for each month are also shown in the table. Figure 8 shows an example of the relationship between monthly solar radiations from observation and estimation with Equation 2 for January, 1993. Generally speaking, the errors of estimation are slightly larger in summer than that in other seasons.

\section{Models to Estimate Yearly Solar Radiation}

The yearly solar radiation can be obtained by summing up the hourly radiation values from Equation 1, as well as by summing up the monthly solar radiation from Equation 2. However, it is impossible to calculate the yearly solar radiation using Equations 1 or 2 without knowing the daily or monthly weather data like cloud cover etc. Therefore an equation was developed to estimate the yearly solar radiation $I y$ with the elevation $H$, latitude $\Psi$ and yearly average cloud cover $\overline{\mathrm{cc}}_{\mathrm{y}}$ as shown in Equation 3:

$$
\mathrm{I}_{\mathrm{y}}=9377.57+0.5124 \cdot \mathrm{H}-55.54 \cdot \psi-587.84 \cdot \overline{\mathrm{CC}_{\mathrm{y}}}
$$

The correlation between observation and estimation of solar radiation by Equation 3 is shown in Fig.9. The root mean square error of estimation with Equation 3 is $231 \mathrm{MJ} / \mathrm{m}^{2}$, which is about $5 \%$ of the average yearly solar radiation over the 24 locations.

The comparisons of yearly solar radiation from 
observation and Equations 1, 2 and 3 are shown in Fig.10. The results from the equations are close to the observation; therefore Equation 3 is the simplest way

when only yearly solar radiation is concerned.

Table 2. Comparison of Observed and Estimated Solar Radiation in the Chinese Locations $\left(\mathrm{MJ} / \mathrm{m}^{2}\right)$

\begin{tabular}{|c|c|c|c|c|c|c|c|c|c|c|c|c|c|c|}
\hline Cities & Month-> & Jan & Feb & Mar & April & May & June & July & Aug & Sept & Oct & Nov & $\mathrm{Dec}$ & SUM \\
\hline \multirow{2}{*}{ BEIJING } & Observed & 249 & 314 & 452 & 529 & 637 & 562 & 539 & 495 & 435 & 344 & 241 & 215 & 5013 \\
\hline & Estimated & 250 & 327 & 490 & 570 & 640 & 588 & 455 & 453 & 426 & 350 & 255 & 230 & 5034 \\
\hline \multirow{2}{*}{ CHANGCHUN } & Observed & 228 & 305 & 458 & 537 & 621 & 642 & 560 & 508 & 454 & 333 & 233 & 190 & 5068 \\
\hline & Estimated & 191 & 270 & 480 & 619 & 714 & 637 & 494 & 501 & 437 & 342 & 221 & 155 & 5064 \\
\hline \multirow{2}{*}{ CHANGSHA } & Observed & 201 & 199 & 246 & 310 & 447 & 435 & 566 & 512 & 426 & 322 & 242 & 225 & 4132 \\
\hline & Estimated & 216 & 239 & 257 & 320 & 419 & 409 & 493 & 470 & 457 & 357 & 242 & 247 & 4127 \\
\hline \multirow{2}{*}{ CHENGDU } & Observed & 146 & 169 & 263 & 343 & 416 & 398 & 408 & 399 & 275 & 203 & 156 & 137 & 3313 \\
\hline & Estimated & 181 & 212 & 298 & 342 & 443 & 357 & 419 & 363 & 294 & 202 & 168 & 159 & 3440 \\
\hline \multirow{2}{*}{ FUZHOU } & Observed & 245 & 254 & 297 & 370 & 440 & 466 & 557 & 546 & 449 & 365 & 277 & 250 & 4517 \\
\hline & Estimated & 261 & 269 & 331 & 385 & 405 & 413 & 526 & 515 & 486 & 382 & 286 & 268 & 4527 \\
\hline \multirow{2}{*}{ GUANGZHOU } & Observed & 258 & 239 & 258 & 278 & 372 & 387 & 442 & 410 & 410 & 407 & 336 & 299 & 4097 \\
\hline & Estimated & 283 & 273 & 291 & 278 & 336 & 337 & 403 & 411 & 424 & 399 & 326 & 294 & 4056 \\
\hline \multirow{2}{*}{ GUIYANG } & Observed & 156 & 179 & 280 & 333 & 396 & 377 & 476 & 485 & 397 & 274 & 232 & 181 & 3766 \\
\hline & Estimated & 170 & 207 & 262 & 357 & 437 & 437 & 469 & 434 & 393 & 259 & 227 & 194 & 3848 \\
\hline \multirow{2}{*}{ HANGZHOU } & Observed & 245 & 271 & 342 & 399 & 494 & 455 & 580 & 513 & 415 & 354 & 261 & 229 & 4558 \\
\hline & Estimated & 269 & 296 & 348 & 414 & 512 & 464 & 589 & 509 & 488 & 397 & 283 & 249 & 4819 \\
\hline \multirow{2}{*}{ HARBIN } & Observed & 183 & 269 & 452 & 540 & 639 & 665 & 612 & 525 & 458 & 309 & 202 & 148 & 5002 \\
\hline & Estimated & 143 & 216 & 423 & 576 & 694 & 571 & 576 & 549 & 450 & 401 & 247 & 156 & 5003 \\
\hline \multirow{2}{*}{ HEFEI } & Observed & 245 & 277 & 374 & 454 & 533 & 483 & 552 & 485 & 438 & 336 & 271 & 227 & 4675 \\
\hline & Estimated & 229 & 311 & 419 & 477 & 512 & 452 & 492 & 422 & 441 & 355 & 261 & 242 & 4614 \\
\hline \multirow{2}{*}{ JINAN } & Observed & 234 & 290 & 422 & 511 & 612 & 566 & 509 & 493 & 439 & 347 & 244 & 205 & 4871 \\
\hline & Estimated & 232 & 319 & 475 & 575 & 612 & 573 & 480 & 433 & 447 & 362 & 257 & 259 & 5023 \\
\hline \multirow{2}{*}{ KUNMING } & Observed & 437 & 459 & 588 & 647 & 579 & 474 & 448 & 455 & 435 & 384 & 391 & 390 & 5684 \\
\hline & Estimated & 479 & 471 & 613 & 689 & 584 & 439 & 450 & 439 & 453 & 443 & 395 & 402 & 5856 \\
\hline \multirow{2}{*}{ LANZHOU } & Observed & 233 & 302 & 440 & 510 & 609 & 618 & 611 & 560 & 424 & 339 & 243 & 209 & 5096 \\
\hline & Estimated & 292 & 309 & 458 & 484 & 585 & 591 & 616 & 554 & 438 & 356 & 284 & 250 & 5217 \\
\hline \multirow{2}{*}{ LHASA } & Observed & 486 & 504 & 632 & 702 & 819 & 789 & 766 & 682 & 638 & 633 & 521 & 483 & 7655 \\
\hline & Estimated & 530 & 511 & 610 & 751 & 823 & 795 & 753 & 774 & 752 & 668 & 526 & 475 & 7968 \\
\hline \multirow{2}{*}{ NANCHANG } & Observed & 226 & 254 & 306 & 364 & 481 & 468 & 581 & 529 & 482 & 391 & 288 & 247 & 4617 \\
\hline & Estimated & 245 & 318 & 335 & 401 & 474 & 451 & 524 & 475 & 495 & 400 & 286 & 258 & 4660 \\
\hline \multirow{2}{*}{ NANJING } & Observed & 242 & 277 & 357 & 426 & 514 & 459 & 526 & 477 & 430 & 332 & 257 & 227 & 4524 \\
\hline & Estimated & 240 & 315 & 383 & 453 & 517 & 450 & 468 & 413 & 425 & 337 & 232 & 241 & 4474 \\
\hline \multirow{2}{*}{ NANNING } & Observed & 215 & 217 & 266 & 337 & 445 & 454 & 500 & 508 & 476 & 423 & 338 & 275 & 4455 \\
\hline & Estimated & 253 & 249 & 314 & 378 & 444 & 413 & 455 & 475 & 507 & 443 & 357 & 283 & 4571 \\
\hline SHFNYANG & Observed & 215 & 300 & 443 & 518 & 590 & 558 & 525 & 506 & 462 & 344 & 230 & 189 & 4880 \\
\hline SHEINYAING & Estimated & 222 & 308 & 488 & 606 & 651 & 548 & 495 & 462 & 427 & 342 & 262 & 192 & 5003 \\
\hline & Observed & 224 & 285 & 428 & 511 & 623 & 541 & 528 & 495 & 438 & 330 & 228 & 203 & 4836 \\
\hline IIANJIN & Estimated & 229 & 312 & 455 & 574 & 673 & 527 & 458 & 441 & 415 & 345 & 225 & 200 & 4855 \\
\hline WHHAN & Observed & 231 & 253 & 320 & 409 & 503 & 476 & 544 & 508 & 438 & 336 & 260 & 227 & 4505 \\
\hline WUHAIN & Estimated & 248 & 340 & 359 & 425 & 519 & 448 & 510 & 450 & 473 & 343 & 252 & 240 & 4607 \\
\hline & Observed & 218 & 259 & 367 & 441 & 536 & 529 & 573 & 529 & 379 & 278 & 211 & 189 & 4508 \\
\hline NIAIV & Estimated & 217 & 282 & 374 & 438 & 512 & 562 & 540 & 491 & 396 & 295 & 229 & 201 & 4537 \\
\hline & Observed & 294 & 358 & 495 & 576 & 648 & 620 & 639 & 583 & 453 & 397 & 310 & 261 & 5634 \\
\hline XIINIING & Estimated & 323 & 352 & 478 & 537 & 655 & 642 & 672 & 630 & 487 & 393 & 336 & 296 & 5799 \\
\hline$Y$ & Observed & 293 & 347 & 503 & 591 & 736 & 698 & 691 & 624 & 496 & 417 & 302 & 264 & 5961 \\
\hline YIINCHUAIN & Estimated & 282 & 350 & 511 & 594 & 718 & 688 & 708 & 645 & 496 & 442 & 307 & 266 & 6007 \\
\hline & Observed & 242 & 300 & 407 & 489 & 585 & 559 & 547 & 512 & 420 & 339 & 253 & 226 & 4879 \\
\hline ZHENG & Estimated & 217 & 310 & 426 & 522 & 572 & 543 & 491 & 467 & 419 & 344 & 247 & 225 & 4784 \\
\hline
\end{tabular}


Table 3. Values of Constants in Equation 2

\begin{tabular}{|c|c|c|c|c|c|c|}
\hline Month & $\mathrm{d} 1$ & $\mathrm{~d} 2$ & $\mathrm{~d} 3$ & $\mathrm{~d} 4$ & $\mathrm{R}$ & RMSE \\
\hline Jan & 832.0 & 0.0244 & -12.590 & -43.28 & 0.97 & 16 \\
\hline Feb & 724.9 & 0.0370 & -7.980 & -42.23 & 0.97 & 18 \\
\hline Mar & 659.7 & 0.0576 & -1.487 & -46.91 & 0.97 & 23 \\
\hline Aprl & 638.6 & 0.0612 & 1.768 & -47.87 & 0.97 & 23 \\
\hline May & 645.7 & 0.0663 & 5.008 & -51.85 & 0.96 & 29 \\
\hline June & 821.2 & 0.0616 & 2.327 & -64.78 & 0.93 & 36 \\
\hline July & 987.5 & 0.0501 & -1.441 & -68.20 & 0.80 & 38 \\
\hline Aug & 894.1 & 0.0548 & -3.101 & -53.70 & 0.75 & 32 \\
\hline Sept & 912.9 & 0.0550 & -6.588 & -58.06 & 0.85 & 27 \\
\hline Oct & 914.9 & 0.0334 & -10.202 & -51.31 & 0.98 & 16 \\
\hline Nov & 806.7 & 0.0180 & -11.240 & -42.69 & 0.97 & 18 \\
\hline Dec & 743.6 & 0.0211 & -11.576 & -36.84 & 0.95 & 21 \\
\hline
\end{tabular}

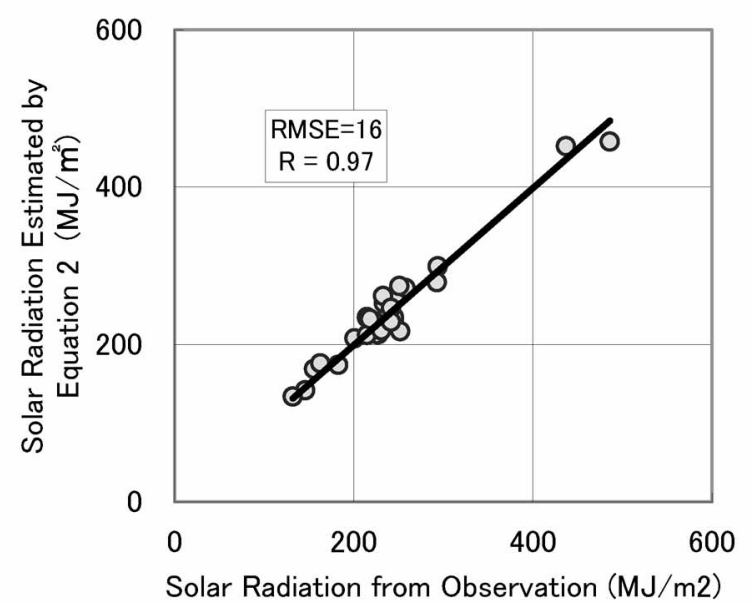

Fig.8. Correlation between Monthly Solar Radiation Values from Observation and Equation 2 (January)

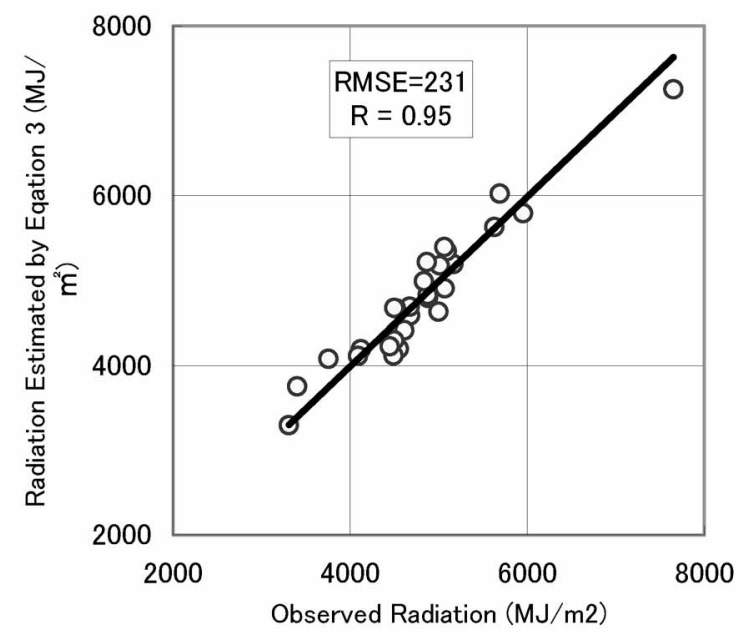

Fig.9. Correlation between Yearly Solar Radiation from Observesion and Equation 3

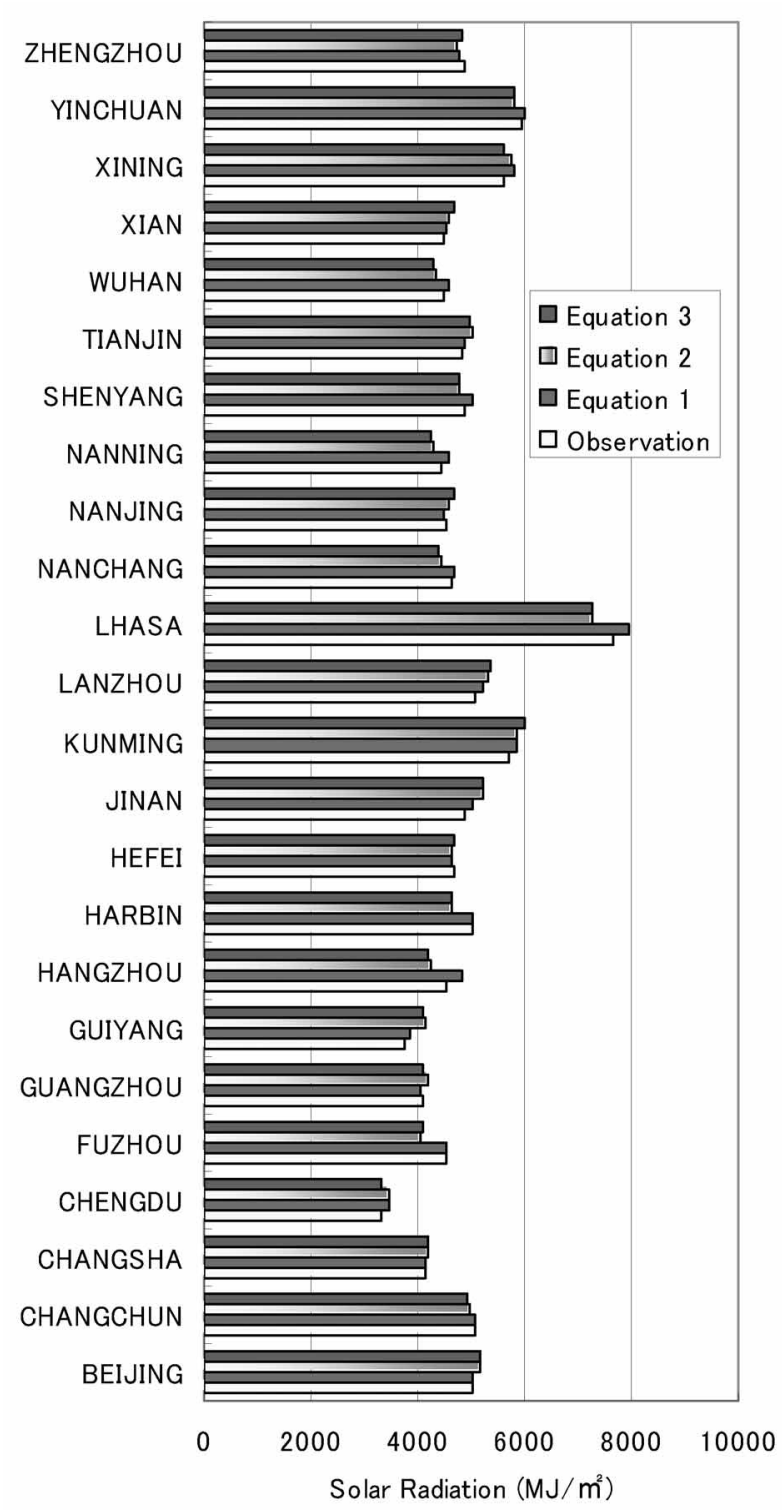

Fig.10. Comparison of Yearly Solar Radiation from Observation and Eqations 1,2 and 3

\section{Conclusions}

In order to estimate solar radiation in Chinese locations, hourly, monthly and yearly models were developed in this paper. The main conclusions of this study are as follows:

1. Hourly models were developed for the 24 cities with variables of cloud cover, temperature changes and relative humidity.

2. Monthly solar radiation can be obtained by summing up the hourly radiation, or by Equation 2 and a set of constants.

3. Three methods of estimating yearly solar radiation were suggested; the results from all the three methods are close to observation. Equation 3 is the simplest way to estimate yearly solar radiation. 


\section{References}

1) Cui, L., Matsuo, Y. Sakamoto, Y. and Nimiya, H. 1996. "The Prediction of Solar Radiation and Its Application" (in Japanese), Summaries of Technical Papers of Annual Meeting, Architectural Institute of Japan, Osaka, Japan

2) Zhang, Q.Y and Asano, K. 2000. "About Typical Weather Data for China" (in Japanese), Summaries of Technical Papers of Annual Meeting, Architectural Institute of Japan, Tokyo, Japan.
3) National Climatic Data Center (NCDC) 1998. International Surface Weather Observations 1982-1997, Volumes 1 through 5, jointly produced by NCDC, National Oceanic and Atmospheric Administration, US Dept. of Commerce, Asheville NC, and the Air Force Combat Climatology Center (AFCCC), US Dept. of Air Force, Asheville NC.

4) Observed Solar Radiation database in 1993 (not published)

5) Architectural Institute of Japan, Expanded AMeDAS Weather Data, Maruzen Co. Ltd, 2000 